\title{
Effects of deoxynivalenol and fumonisins fed in combination on beef cattle: health
} and performance indices

\author{
J.M. Duringer ${ }^{1 *}$, H.L. Roberts ${ }^{2}$, B. Doupovec $^{3}$, J. Faas ${ }^{3}$, C.T. Estill ${ }^{4}$, D. Jiang ${ }^{5}$ and D. Schatzmayr ${ }^{3}$ \\ ${ }^{1}$ Department of Environmental \& Molecular Toxicology, College of Agricultural Sciences, Oregon State University, Corvallis, \\ OR 97331, USA; ${ }^{2}$ Department of Animal \& Rangeland Sciences, College of Agricultural Sciences, Oregon State University, \\ Corvallis, OR 97331, USA; ${ }^{3}$ BIOMIN Research Center, Technopark 1, 3430 Tulln, Austria; ${ }^{4}$ Department of Clinical Sciences, \\ Carlson College of Veterinary Medicine, Oregon State University, Corvallis, OR 97331, USA; ${ }^{5}$ Department of Statistics, \\ College of Science, Oregon State University, Corvallis, OR 97331, USA; jennifer.duringer@oregonstate.edu
}

Received: 11 February 2020 / Accepted: 2 June 2020

(c) 2020 Wageningen Academic Publishers

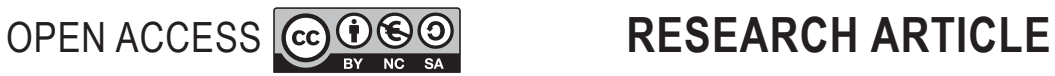

\begin{abstract}
Interactions between livestock management practices and toxicological outcomes of mycotoxin exposure may explain the range of tolerable toxin levels reported for various species. In the current study, we investigated the effect of concurrent mycotoxin exposure with a high starch diet in 12 beef steers in a partial cross-over experiment using a 21-day treatment period, followed by a 14-day clearance. During the treatment period, animals were assigned to one of two diets: a low mycotoxin control total mixed ration (TMR) $(0.2 \pm 0.1 \mathrm{mg}$ deoxynivalenol (DON) and $0.2 \pm 0.2 \mathrm{mg}$ fumonisins (FUM) $/ \mathrm{kg}$ TMR) and a high mycotoxin TMR treatment $(1.7 \pm 0.2 \mathrm{mg}$ DON and $3.5 \pm 0.3 \mathrm{mg}$ $\mathrm{FUM} / \mathrm{kg}$ TMR). We evaluated the impacts of these mycotoxins on performance, physiology and biochemistry; and the ability of the clearance period to return animals to a naïve state in the cross-over model. The lack of acute ruminal acidosis observed indicates that the animals were able to withstand the physiological stresses of the high starch diet, while toxicological outcomes were manifested in minor perturbations of biochemistry and outright performance of exposed animals. Aspartate aminotransferase, cholesterol, fibrinogen and leukocyte count were increased while sorbitol dehydrogenase, bile acids and mean corpuscular volume were decreased in treatment-fed steers, yet were not significantly different than those from control-fed animals. Fusarium toxin exposure significantly decreased ruminal fluid $\mathrm{pH}$, with the clearance period returning animals to a naïve state, as it did for most of the molecular variables measured. Conversely, treatment-fed animals continued to exhibit significantly lower average weekly body weight throughout the treatment period and the first week of the clearance period. While the risk of adverse health effects to fattening cattle from similar doses of DON or FUM as used in the current study is considered low, additional work should be directed towards minimising production losses due to these feed contaminants.
\end{abstract}

Keywords: beef cattle, Fusarium, ruminal acidosis, deoxynivalenol, fumonisins, cross-over experiment

\section{Introduction}

Fungi of the genera Fusarium may produce a number of metabolites which cause toxicity in animals, collectively known as Fusarium toxins. Among the Fusarium toxins of greatest concern to livestock producers are deoxynivalenol (DON, a type B trichothecene) and the fumonisins (FUM, especially fumonisin $B_{1}, B_{2}$ and $B_{3}$ ) (Morgavi and Riley, 2007), due to both their prevalence in important livestock feedstuffs (Streit et al., 2013; US Grains Council, 2016), and their toxic effects on livestock species of economic importance (Bondy and Pestka, 2000; Prelusky et al., 1994). Safety limits set by the United States Food \& Drug Administration for finishing beef cattle $(60 \mathrm{mg} / \mathrm{kg}$ FUM and $10 \mathrm{mg} / \mathrm{kg}$ DON (US Food and Drug Administration, 2018 a,b)) indicate that they are more resistant to development of toxicoses from these compounds than most other livestock species: guidance values for breeding/ milking ruminants are $30 / 5 \mathrm{mg} / \mathrm{kg}$; swine are $20 / 5 \mathrm{mg} / \mathrm{kg}$; and equine are $5 / 5 \mathrm{mg} / \mathrm{kg}$ FUM/DON, respectively. 
Poultry are the only species more tolerant of FUM, with guidance levels set at $100 \mathrm{mg} / \mathrm{kg}$ FUM; they match the value recommended for finishing beef cattle for DON at $10 \mathrm{mg} / \mathrm{kg}$. However, previous work in both dairy (Baker and Rottinghaus, 1999; Dänicke et al., 2005; Korosteleva et al., 2007, 2009; Mathur et al., 2001) and beef (Osweiler et al., 1993) cattle have shown that, while able to consume greater concentrations of DON and FUM than some livestock species, cattle are nonetheless sensitive to the immunotoxic and hepatotoxic effects of these compounds. In vitro studies have demonstrated that bovine immune cells may be more sensitive to Fusarium toxins than those of swine or poultry (Novak et al., 2018). Of growing interest is the toxicity of these compounds in conjunction with intensive management practices, veterinary pathologies and dietary cofactors which may predispose animals to adverse disease events associated with Fusarium toxins. As DON and FUM are also commonly associated with high starch grains (e.g. maize) (Gruber-Dorninger et al., 2019), the practice of feeding concentrate diets in feedlot settings for maximum growth potential may increase the total level of exposure at a time when animals are experiencing the physiological stress of rapid growth and energy turnover. This is further compounded by evidence that the composition of the rumen microbiome is altered when animals are switched from a primarily roughage feed to a high concentrate diet (Cammack et al., 2018; Fink-Gremmels, 2008), which may affect the host's ability to detoxify DON and other mycotoxins (Valgaeren et al., 2019). Preliminary evidence using in vitro incubations with rumen fluid from dairy cows suggested that low ruminal $\mathrm{pH}$ (mimicking sub-acute rumen acidosis) and lactation stage affected degradation of DON, nivalenol, zearalenone (ZEN) and enniatin B (Debevere et al., 2019).

To date, few studies have investigated the toxic effects of Fusarium toxins on hepatic function and immune status in beef cattle on high starch finishing rations. Recent reviews on risks to animal health summarized current knowledge and set a No Observable Adverse Effect Level (NOAEL) in fattening cattle of $31 \mathrm{mg} / \mathrm{kg}$ in feed for FUM (EFSA, 2018), and $18 \mathrm{mg} / \mathrm{kg}$ in feed for DON (EFSA, 2017). To examine these effects in a large animal model, a crossover study design may be utilized to reduce animal numbers needed, study cost and subject-subject variation (Bate and Boxall, 2008; Kaps and Lamberson, 2009). Assumptions made with this design are that the animal returns to baseline physiology during the clearance period, thus making them as naïve to the second treatment as they were to the first. However, residual effects of DON and FUM may persist due to tissue deposition (EFSA, 2018; Pestka et al., 2008; Prelusky et al., 1994; Sobrova et al., 2010) or through fundamental alterations to the affected systems, from which recovery may take substantial time, extending past the clearance window (Joffe, 1986).
The current work aimed to investigate potential effects of DON and FUM fed via a total mixed ration (TMR) on feedlot cattle performance, as well as immune system and hepatic function; and to evaluate the validity of the crossover model by characterising persistence of these effects through a period of negligible mycotoxin exposure in the clearance period. Evaluation of the effects of mycotoxins was done using thorough examination of blood, liver, energy, complete blood count (CBC) and other health/ performance parameters that have not been previously assessed in such depth in beef cattle. This information could have far-reaching implications for the beef cattle industry for animals finished in feedlots, who are typically under increased physiological stress and therefore may be more susceptible to the effects of mycotoxins.

\section{Materials and methods}

\section{Reagents, standards and laboratory conditions}

Acetonitrile and methanol (LC-MS grade) were purchased from JT Baker (Phillipsburg, NJ, USA). Formic and acetic acid (analytical grade) were procured from Millipore (Billerica, MA, USA). Sphinganine and sphingosine were purchased from Avanti Polar Lipids (Alabaster, AL, USA). Volatile fatty acids (4-methylvaleric, propionic, butyric, iso-butyric, valeric and iso-valeric) were obtained from Sigma-Aldrich (St. Louis, MO, USA). Water (18 $\mathrm{m} \Omega$ ) was derived from an ELGA Ultra PureLab water system (Cary, NC, USA).

\section{Study design}

All experimental parameters, procedures and sampling were approved under Animal Care and Use Protocol \#4986, obtained through Oregon State University's (OSU) Institutional Animal Care and Use Committee. A timeline of the experiment is described in Supplementary Table S1. Twelve beef steers (black Angus, sired from the same bull on one farm, weighing $\sim 400 \mathrm{~kg}$ ) were purchased through a commercial feedlot (Simplot Feedyard, Pasco, WA, USA). Upon arrival on day -43 , all animals were treated metaphylactically with a single dose of tulathromycin (10 ml of $100 \mathrm{mg}$ tulathromycin/ml; Zoetis, Parsippany, NJ, USA) and assessed by a veterinarian for overall health. This is well beyond the withdrawal period for this compound (18 days); further, tulathromycin has shown no significant effects on the ruminal microbiome of cattle (Doster et al., 2018). Steers were housed together in one large pen for the duration of the study. Animals were fitted with electronic collars (American Calan, Northwood, NH, USA) on day -14 for individual access to their assigned treatment ration. A natural photoperiod was adopted. Environmental temperature and humidity data was accessed through records kept by the National Oceanic and Atmospheric Administration's National Weather Service, US Department 
of Commerce for Corvallis, OR, USA. Temperatures ranged from a low of $-6^{\circ} \mathrm{C}$ to a high of $21^{\circ} \mathrm{C}$ and an average of $7^{\circ} \mathrm{C}$ for the pre-trial phase. For the treatment and clearance periods, temperatures had a low, high and average of -1 , $28,11^{\circ} \mathrm{C}$ and $4,31,15^{\circ} \mathrm{C}$, respectively.

Animals were weighed daily pre-prandial. These weights were analysed as weekly body weight. Body condition score was evaluated by a trained veterinarian before group assignment and at the end of each feeding phase (days -4 , 21 and 35) (Paschal, 2017). These scores were recorded on a scale of $1-9$, with 1 representing a severely emaciated animal and 9 representing an obese animal. Prior to group assignment, all animals were again evaluated on day -4 by a veterinarian for overall health and assessed for body condition score. Animals were blocked to treatment by feed intake during the week prior to day 0 . The feeding experiment consisted of a three week mycotoxin challenge period (days 0-20), followed by a two week clearance period (days 21-35). The total study duration was 79 days.

\section{Diet formulation}

On day -43 , animals were placed on a TMR consisting of tall fescue hay (Zehner Farms, Lebanon OR, USA), flaked maize, soybean meal and PNW Ultramin 12-12 Se vitamin supplement (Ca 12.0-14.0\%, P 12.0\%, salt 3.0-4.0\% and not less than the following: Mg 2.75\%, Co $20 \mathrm{mg} / \mathrm{kg}$, Cu 3.5 ng/kg, I 200 mg/kg, Mn 3.5 ng/kg, Se 53.0 mg/kg, Zn 7.5 ng/kg, vitamin A 66,139 IU/kg, vitamin D 66,139 $\mathrm{IU} / \mathrm{kg}$, vitamin E 1,102 IU/kg) (all from CHS Nutrition, Harrisburg, OR, USA) until day -15 , with incremental increases in the maize component of the diet over this time frame. Beginning on day -14 , flaked maize was replaced with ground maize (CHS Nutrition) to mimic feedstuffs fed during the trial period.

Naturally contaminated ground maize grain contained DON and FUM; this was supplemented with culture material provided by BIOMIN Research Center (Tulln, Austria). For the culture material, the strain Fusarium graminearum was grown on rice and used to produce DON (Altpeter and Posselt, 1994). The homogenised extract contained $1.99 \mathrm{~g} / \mathrm{kg}$ DON and was mixed via the ground maize into the TMR to achieve an average concentration of $1.7 \pm 0.2 \mathrm{mg}$ DON and $3.5 \pm 0.3 \mathrm{mg}$ FUM per $\mathrm{kg}$ TMR for the treatment diet (control diet contained $0.2 \pm 0.1 \mathrm{mg}$ DON and $0.2 \pm 0.2 \mathrm{mg}$ FUM per $\mathrm{kg}$ TMR). Our aim in choosing these concentrations was to avoid overt acute toxicosis so that more subtle changes in performance and physiological parameters that are more typically experienced by beef cattle in feedlot environments could be delineated. TMRs from both groups were sampled each day, pooled by week and sent to an accredited commercial laboratory for mycotoxin quantitation; FUM reflects a value of fumonisin $B_{1}, B_{2}$ and $B_{3}$ added together (additional mycotoxins were included in the multi-mycotoxin panel that was tested on the weekly TMR samples. Of these, only nivalenol and ZEN were detected above the detection limit in the treatment samples (average 242 and $85 \mathrm{ug} / \mathrm{kg}$ ). All other mycotoxins (aflatoxins, ochratoxin, acetyl-deoxynivalenol, fusarenon-X, HT-2 toxin, T-2 toxin, neosolaniol and diacetoxyscirpenol) were below the limit of detection). Nutrient profiling was performed twice during both the challenge (day 0 and 14) and recovery (day 21 and 28) phases by an accredited commercial laboratory for diets and individual diet components (Supplementary Table S2). The TMR was provided daily in the morning for ad libitum consumption through electronic feeding gates controlled by magnetic collars on each animal. Drinking water was supplied ad libitum.

\section{Blood collection}

Blood was collected from each steer on days $0,7,14,21$, 28 , and 35 at approximately the same time of morning into Vacutainer ${ }^{\oplus}$ tubes (BD, Franklin Lakes, NJ, USA) containing EDTA as an anticoagulant and into Vacutainer tubes containing no anticoagulant. Tubes were stored at room temperature then were either separated for serum (then frozen at $-20{ }^{\circ} \mathrm{C}$ for evaluation of sphinganine/sphingosine ratio) or delivered the same-day to an accredited veterinary diagnostic laboratory for determination of energy-protein indices (glucose, non-esterified fatty acids (NEFA), $\beta$-hydroxy-butyrate $(\beta$-HBA), blood urea nitrogen (BUN), albumin, creatinine, creatinine kinase $(\mathrm{CK})$, triglycerides, total protein, and sorbitol dehydrogenase (SDH)); mineral metabolism/electrolyte measurements (calcium $(\mathrm{Ca})$, phosphorus $(\mathrm{P})$, magnesium $(\mathrm{Mg})$, sodium $(\mathrm{Na})$, potassium $(\mathrm{K})$, chloride $(\mathrm{Cl})$, carbon dioxide $\left(\mathrm{CO}_{2}\right)$, anion gap); evaluation of liver functionality (aspartate aminotransferase (AST), $\gamma$-glutamyl transpeptidase (GGT), total bilirubin, bile acids, cholesterol); immune function (fibrinogen); and complete blood count ( $\mathrm{CBC})$, including red blood cells, white blood cells, haemoglobin, haematocrit, platelets, packed cell volume (PCV), mean corpuscular volume (MCV), mean corpuscular haemoglobin concentration (MCHC) and plasma protein). For the blood chemistries, a Beckman Coulter (Pasadena, CA, USA) AU480 chemistry analyser was used. The CBC's were performed using a Siemens (Munich, Germany) ADVIA 120, with the differential performed manually using 100 cells. The PCV and fibrinogen were determined manually. PCV was spun in a micro-haematocrit centrifuge, while the fibrinogen was performed by heat precipitation.

\section{Faecal collection}

Faeces were collected from the rectum on days $0,7,14$, 21, 28, and 35. Samples were weighed then dried in a freeze-drier (HarvestRight, North Salt Lake, UT, USA) overnight and stored at $-20^{\circ} \mathrm{C}$ until use. Samples were 
ground in a Cyclotec sample mill using a $1.0 \mu \mathrm{m}$ screen (Foss, Hillerød, Denmark), then shipped to an accredited commercial laboratory for faecal evaluation $(\mathrm{N}$, ammonium $\mathrm{N}$, organic $\mathrm{N}, \mathrm{P}, \mathrm{P}$ equivalent, $\mathrm{K}$, potash equivalent, total solids, ash, and $\mathrm{Cl}$ ).

\section{Whole ruminal fluid collection}

The site used for needle insertion was clipped and surgically prepared, followed by administration of a local anaesthetic. A small incision was made and whole ruminal fluid was collected using a $16 \mathrm{~g}$ rumenocentesis needle on days $0,7,21$, and 28 , and from excised rumens at day $35 . \mathrm{pH}$ was immediately measured using a pH meter (Corning, Swedesboro, NJ, USA), then remaining fluid was strained through two layers of fine cheesecloth and aliquoted for analysis. For rumen fluid ammonia quantitation, metaphosphoric acid $(25 \% \mathrm{w} / \mathrm{v})$ was added to each sample at a rate of $1: 4(\mathrm{v} / \mathrm{v})$. All rumen fluid samples were stored at $-20^{\circ} \mathrm{C}$ until further analysis.

\section{Liver biopsy}

Livers were biopsied on days 0,21 and 35 . The area used for puncture was clipped and surgically prepared, followed by administration of a local anaesthetic. A small incision was made and a biopsy needle (Biopty-Cut, Bard, Covington, GA, USA) used to collect liver tissue (approximately $1.5 \mathrm{~g}$ ). Tissue was immediately placed into $10 \%$ neutral buffered formalin, then transferred the same day to an accredited veterinary diagnostic laboratory for histological evaluation.

\section{Necropsy}

At the conclusion of the trial, animals were euthanized by captive bolt and exsanguination. Heart, lung, liver, kidney, spleen, rumen wall, mesenteric lymph node and small intestine samples were collected for both histological analysis by a pathologist (immediately placed into 10\% neutral buffered formalin, then transported to an accredited veterinary diagnostic laboratory) and for storage in a $-80^{\circ} \mathrm{C}$ freezer. Whole heart, lung, liver, kidney and spleen were also weighed, and gross observations recorded.

\section{Sphinganine/sphingosine ratio}

Serum was processed for sphinganine/sphingosine ratio ( $\mathrm{Sa} / \mathrm{So}$ ) determination based upon a previous method (Grenier et al., 2015). Samples were thawed then prepared for analysis via LC-MS/MS on an ABI/SCIEX 3200 QTRAP system; Applied Biosystems, Foster City, CA, USA) using electrospray ionization, with separation performed using a Perkin Elmer (Waltham, MA, USA) Series 200 HPLC connected to a Kinetix C18 column $(150 \times 2.1 \mathrm{~mm}, 2.6 \mu \mathrm{m}$, Phenomenex, Torrance, CA, USA) with a ULTRA security guard cartridge of similar packing. Collision energy, declustering potential, entrance potential and dwell time for the Q1 and Q3 quantifier and qualifier ions were optimised as follows: Sa quantifier $(302.3 \rightarrow 284.4) 17 \mathrm{eV}, 31 \mathrm{~V}, 5.5 \mathrm{~V}$, 150 msec; Sa qualifier $(302.3 \rightarrow 60.1) 33 \mathrm{eV}, 36 \mathrm{~V}, 4.0 \mathrm{~V}, 150$ msec; So quantifier $(300.3 \rightarrow 282.3) 15 \mathrm{eV}, 21 \mathrm{~V}, 6.0 \mathrm{~V}, 150$ msec; So qualifier $(300.3 \rightarrow 252.3) 21 \mathrm{eV}, 21 \mathrm{~V}, 5.5 \mathrm{~V}, 150$ msec. MultiQuant v.3.0.1 (Applied Biosystems) was used to quantitate samples against external calibrators. Limit of quantification (LOQ) was $1 \mathrm{ng} / \mathrm{ml}$ for both compounds.

\section{Whole ruminal fluid volatile fatty acids}

Whole, strained ruminal fluid was thawed at $4{ }^{\circ} \mathrm{C}$, then briefly homogenised and centrifuged at 5,000 $\times g$ for $5 \mathrm{~min}$. A homogenised aliquot of supernatant was added to chilled ultrapure $\mathrm{H}_{2} \mathrm{O}$ and an internal standard solution containing 4-methylvaleric acid in metaphosphoric acid and formic acid. This mixture was briefly vortexed then stored at $4{ }^{\circ} \mathrm{C}$ for $30 \mathrm{~min}$ in the dark. Samples were centrifuged at 10,000 $\times \mathrm{g}$ for $15 \mathrm{~min}$ and the supernatant filtered through a $0.2 \mu \mathrm{m}$ PTFE filter before analysis by gas chromatography (GC).

GC analysis was performed with an Agilent 6890 GC (Agilent Technologies Inc., Wilmington, DE, USA) equipped with an Agilent 7840 autosampler, flame ionization detector (temperature set at $220^{\circ} \mathrm{C}$ ) and Stabilwax-DA fused silica column $(30 \mathrm{~m} \times 530 \mu \mathrm{m} \times 0.25 \mu \mathrm{m}$, Restek, Bellefonte, PA, USA). Peak areas were calculated using HewlettPackard ChemStation software (Agilent Technologies Inc.). Volatile fatty acids (VFAs) concentrations were determined against a standard curve using eight concentrations of neat standards (acetic, propionic, butyric, iso-butyric, valeric and isovaleric acids), with 4-methylvaleric acid acting as an internal standard for both samples and standards. The LOQ was $0.03 \mathrm{mM}$ for acetic and propionic acids, and $0.01 \mathrm{mM}$ for butyric, iso-butyric, valeric and iso-valeric acids.

\section{Whole ruminal fluid ammonia and protein concentration}

Whole ruminal fluid ammonia concentration was measured following methods developed previously (Broderick and Kang, 1980). Plate readings at $650 \mathrm{~nm}$ were taken with a SpectraMax PLUS 384 plate reader (Molecular Devices, San Jose, CA, USA) and analysed using SoftMax Pro 6.3 software (Molecular Devices). The LOQ was $1 \mathrm{mg} / \mathrm{dl} \mathrm{NH}_{4} \mathrm{Cl}$ equivalent.

Whole ruminal fluid protein levels were measured using modifications of a commercially available Bradford reagent kit (VWR, Radnor, PA, USA). Plate readings at $595 \mathrm{~nm}$ were taken with the same plate reader and software used above. The LOQ was $2.5 \mu \mathrm{g} / \mathrm{ml}$ bovine serum albumin equivalent. 


\section{Data handling and statistical analysis}

Statistical analysis was performed using R v3.6 (R Core Team, 2019) and a linear regression model. Outliers were removed (1.5×IQR). Baseline values were excluded from analysis to serve as covariates. With the exception of $\mathrm{pH}$ readings and performance data (body weight and feed intake), all data were natural log transformed prior to analysis. For each of the non-baseline time points separately, we performed linear regression, incorporating the baseline values as a covariate. For each parameter, the final statistical model included diet and baseline measurement of each parameter as main effects. Multiple testing was accounted for using the Benjamini-Hochberg procedure to control for false discovery rate (FDR) within the treatment (weeks 1-3) and clearance (weeks 4-5) periods. As the aim of this trial was to identify a large proportion of biometrics which may be even subtly affected by a low dose and exposure time to DON and FUM, adjusted $P$-values were considered significant at $P \leq 0.10$. Adjusted $P$-values between 0.1 and 0.2 were discussed as suggestive evidence. Organ weights were an exception to this analysis, as these parameters were measured exclusively at the study conclusion. Consequently, organ weights were compared using a t-test assuming unequal variance; unadjusted $P$-values were considered significant at $P \leq 0.05$.

\section{Results and discussion}

Previous studies and reviews examining the effects of DON or FUM on fattening/finishing beef cattle identified decreased rate of body weight gain, and toxicity to the liver, kidney and immune system as the main toxic endpoints (Baker and Rottinghaus, 1999; Dänicke et al., 2005, 2018; EFSA, 2017, 2018; Osweiler et al., 1993). In the present study, we utilized an average concentration in the TMR of $1.7 \mathrm{mg}$ DON and $3.5 \mathrm{mg}$ FUM per $\mathrm{kg}$ TMR in the diet in a partial crossover study with 12 black Angus steers to examine the effects of these mycotoxins on overall beef cattle physiology, along with hepatic and immune function in more depth than previous works. While higher than levels found in finished feed on average (Gruber-Dorninger et al., 2019), these concentrations fall well below the current recommended safety limits set by the United States Food \& Drug Administration for animal feed $(60 \mathrm{mg} / \mathrm{kg}$ FUM and $10 \mathrm{mg} / \mathrm{kg}$ DON) (US Food and Drug Administration, 2018a,b), and the European Food Safety Authority (50 mg/kg FUM and $5 \mathrm{mg} / \mathrm{kg}$ DON) (EC, 2006) for ruminants greater than three months old being raised for human consumption. Thus, the effects seen in these cattle should mirror what would be expected in a commercial finishing operation.

\section{Gross animal growth data}

Of most significance, the average weekly body weight was decreased in the treatment group for weeks 1-4. (Table 1, $P \leq 0.20$ ). The end of the treatment period showed the most disparity between the groups, in which treatment group animals weighed $16 \mathrm{~kg}$ less than the controls, despite both groups beginning the experiment with similar starting weights. The animals in the treatment group showed partial recovery through the clearance phase, weighing $14 \mathrm{~kg}$, then $10 \mathrm{~kg}$ less than the control group in weeks 4 and 5, respectively (Table 1). Average daily feed intake was significantly different only for week 2 (Table $1, P \leq 0.10$ ), indicating that treatment-fed animals mirrored control animal feed intake for the remainder of the study. The European Food Safety Authority Panel on Contaminants in Food (EFSA, 2017) review found reduced weight gain as a generalized outcome for most animal species exposed to DON; however, the observations of reduced weight gain and its corollaries of reduced feed intake and altered carcass characteristics were not observed in a study which fed $6-18 \mathrm{mg} / \mathrm{kg}$ DON to steers over 166 days (DiCostanzo

Table 1. Gross animal body weight and feed intake measurements of beef cattle exposed to Fusarium mycotoxins for 21 days, followed by a 14-day clearance period. ${ }^{1}$

\begin{tabular}{|c|c|c|}
\hline & $\begin{array}{l}\text { Average weekly } \\
\text { body weight (kg) }\end{array}$ & $\begin{array}{l}\text { Average daily feed } \\
\text { intake }(\mathrm{kg})\end{array}$ \\
\hline Baseline & - & - \\
\hline Control & $414 \pm 9$ & $8.3 \pm 0.5$ \\
\hline Treatment & $416 \pm 12$ & $9.3 \pm 0.6$ \\
\hline Week 1 & $0.10^{*}$ & 0.31 \\
\hline Control & $424 \pm 10$ & $9.6 \pm 0.7$ \\
\hline Treatment & $420 \pm 12$ & $8.7 \pm 0.7$ \\
\hline Week 2 & $0.05^{\star}$ & $0.10^{*}$ \\
\hline Control & $434 \pm 10$ & $9.7 \pm 0.6$ \\
\hline Treatment & $425 \pm 14$ & $9.0 \pm 1.2$ \\
\hline Week 3 & $0.05^{\star}$ & 0.45 \\
\hline Control & $444 \pm 10$ & $9.4 \pm 0.6$ \\
\hline Treatment & $428 \pm 15$ & $9.2 \pm 0.9$ \\
\hline Week 4 & $0.14 t$ & 0.34 \\
\hline Control & $450 \pm 10$ & $10.0 \pm 0.3$ \\
\hline Treatment & $436 \pm 17$ & $8.9 \pm 0.7$ \\
\hline Week 5 & 0.32 & 0.43 \\
\hline Control & $455 \pm 9$ & $9.0 \pm 0.7$ \\
\hline Treatment & $445 \pm 16$ & $9.7 \pm 0.3$ \\
\hline \multicolumn{3}{|c|}{$\begin{array}{l}1 \text { Treatment period lasted three weeks, followed by a } 2 \text {-week clearance } \\
\text { period (weeks } 4 \text { and } 5 \text { ), and included } n=6 \text { animals per group. Values are } \\
\text { observed means } \pm \text { standard errors before any baseline value correction } \\
\text { Benjamini-Hochberg adjusted } P \text {-values are indicated in italics; }{ }^{*}=\text { adjustec } \\
P \text {-value } \leq 0.10 ; \dagger=\text { adjusted } P \text {-values between } 0.1 \text { and } 0.2 \text { were considerec } \\
\text { suggestive evidence. }\end{array}$} \\
\hline
\end{tabular}


Table 2. Blood chemistry: energy-protein, liver and immune system indices of beef cattle exposed to Fusarium mycotoxins for 21 days, followed by a 14-day clearance period. ${ }^{1}$

\begin{tabular}{|c|c|c|c|c|c|c|c|c|c|c|c|c|}
\hline & $\begin{array}{l}\text { Glucose } \\
\text { (mg/dl) }\end{array}$ & $\begin{array}{l}\text { Creatinine } \\
\text { kinase } \\
(\mathrm{U} / \mathrm{I})\end{array}$ & $\begin{array}{l}\text { Tri- } \\
\text { glycerides } \\
\text { (mg/dl) }\end{array}$ & $\begin{array}{l}\text { SDH } \\
(U / I)\end{array}$ & $\begin{array}{l}\text { AST } \\
\text { (U/I) }\end{array}$ & $\begin{array}{l}\text { Bile acids } \\
(\mu \mathrm{mol} / \mathrm{l})\end{array}$ & $\begin{array}{l}\text { Cholesterol } \\
\text { (mg/dl) }\end{array}$ & $\begin{array}{l}\text { Fibrinogen } \\
\text { (mg/dl) }\end{array}$ & $\begin{array}{l}\text { Plasma } \\
\text { protein } \\
(\mathrm{g} / \mathrm{dl})\end{array}$ & $\begin{array}{l}\text { Sphinganine } \\
\text { (ng/ml) }\end{array}$ & $\begin{array}{l}\text { Sphingosine } \\
\text { (ng/ml) }\end{array}$ & $\begin{array}{l}\text { Sa/So } \\
\text { ratio }\end{array}$ \\
\hline Baseline & - & - & - & - & - & - & - & - & - & - & - & - \\
\hline Control & $91 \pm 5$ & $178 \pm 15$ & $16 \pm 2$ & $32 \pm 11$ & $62 \pm 5$ & $29.6 \pm 9.8$ & $70 \pm 3$ & $558 \pm 80$ & $7.6 \pm 0.1$ & $0.96 \pm 0.06$ & $1.42 \pm 0.27$ & $0.77 \pm 0.09$ \\
\hline Treatment & $94 \pm 6$ & $197 \pm 19$ & $17 \pm 2$ & $37 \pm 10$ & $77 \pm 7$ & $41.3 \pm 10.9$ & $65 \pm 7$ & $383 \pm 31$ & $7.6 \pm 0.2$ & $1.01 \pm 0.05$ & $1.63 \pm 0.21$ & $0.68 \pm 0.09$ \\
\hline Week 1 & 0.61 & 0.67 & 0.67 & 0.98 & 0.37 & 0.73 & 0.37 & 0.67 & 0.87 & 0.86 & 0.76 & 0.87 \\
\hline Control & $83 \pm 2$ & $171 \pm 19$ & $17 \pm 1$ & $21 \pm 2$ & $66 \pm 5$ & $32.8 \pm 3.9$ & $72 \pm 4$ & $500 \pm 45$ & $7.5 \pm 0.1$ & $0.97 \pm 0.08$ & $1.29 \pm 0.12$ & $0.70 \pm 0.11$ \\
\hline Treatment & $88 \pm 3$ & $167 \pm 31$ & $21 \pm 3$ & $27 \pm 4$ & $71 \pm 8$ & $27.5 \pm 6.1$ & $79 \pm 8$ & $560 \pm 68$ & $7.6 \pm 0.1$ & $0.91 \pm 0.03$ & $1.45 \pm 0.12$ & $0.67 \pm 0.10$ \\
\hline Week 2 & 0.89 & 0.37 & 0.97 & 0.61 & 0.86 & 0.67 & 0.86 & 0.42 & 0.36 & 0.36 & 0.61 & 0.86 \\
\hline Control & $92 \pm 1$ & $180 \pm 22$ & $16 \pm 2$ & $41 \pm 12$ & $74 \pm 6$ & $35.4 \pm 5.3$ & $76 \pm 3$ & $517 \pm 48$ & $7.4 \pm 0.1$ & $1.53 \pm 0.12$ & $2.66 \pm 0.48$ & $0.65 \pm 0.10$ \\
\hline Treatment & $93 \pm 5$ & $146 \pm 20$ & $18 \pm 2$ & $27 \pm 11$ & $71 \pm 7$ & $31.3 \pm 12.1$ & $73 \pm 7$ & $600 \pm 52$ & $7.9 \pm 0.1$ & $1.21 \pm 0.13$ & $2.38 \pm 0.49$ & $0.56 \pm 0.06$ \\
\hline Week 3 & 0.61 & 0.44 & 0.86 & 0.67 & 0.80 & 0.37 & 0.73 & 0.86 & 0.61 & 0.86 & 0.97 & 0.87 \\
\hline Control & $85 \pm 1$ & $189 \pm 25$ & $17 \pm 2$ & $22 \pm 3$ & $72 \pm 5$ & $32.5 \pm 5.6$ & $74 \pm 6$ & $517 \pm 54$ & $7.8 \pm 0.2$ & $0.92 \pm 0.04$ & $1.45 \pm 0.17$ & $0.63 \pm 0.06$ \\
\hline Treatment & $81 \pm 1$ & $166 \pm 26$ & $20 \pm 3$ & $25 \pm 5$ & $75 \pm 3$ & $15.5 \pm 3.2$ & $77 \pm 7$ & $467 \pm 33$ & $8.2 \pm 0.1$ & $0.98 \pm 0.05$ & $1.63 \pm 0.20$ & $0.60 \pm 0.05$ \\
\hline Week 4 & 0.57 & 0.57 & 0.57 & 0.57 & 0.95 & 0.57 & 0.57 & 0.83 & 0.57 & 0.57 & 0.91 & 0.91 \\
\hline Control & $81 \pm 2$ & $206 \pm 29$ & $14 \pm 2$ & $26 \pm 5$ & $71 \pm 3$ & $14.1 \pm 2.5$ & $76 \pm 6$ & $533 \pm 33$ & $7.9 \pm 0.1$ & $1.20 \pm 0.08$ & $1.95 \pm 0.37$ & $0.68 \pm 0.08$ \\
\hline Treatment & $78 \pm 2$ & $171 \pm 25$ & $17 \pm 2$ & $38 \pm 8$ & $77 \pm 7$ & $27.6 \pm 9.2$ & $68 \pm 3$ & $500 \pm 52$ & $8.4 \pm 0.2$ & $1.14 \pm 0.07$ & $1.98 \pm 0.24$ & $0.63 \pm 0.11$ \\
\hline Week 5 & 0.57 & 0.74 & 0.57 & 0.49 & 0.74 & 0.57 & 0.57 & 0.92 & 0.57 & 0.83 & 0.91 & 0.57 \\
\hline Control & $84 \pm 3$ & $192 \pm 46$ & $16 \pm 1$ & $38 \pm 9$ & $77 \pm 6$ & $50.1 \pm 16.2$ & $72 \pm 8$ & $580 \pm 136$ & $7.8 \pm 0.3$ & $0.71 \pm 0.08$ & $1.10 \pm 0.23$ & $0.65 \pm 0.11$ \\
\hline Treatment & $79 \pm 3$ & $159 \pm 26$ & $21 \pm 3$ & $24 \pm 4$ & $78 \pm 4$ & $34.1 \pm 9.1$ & $80 \pm 4$ & $450 \pm 43$ & $8.2 \pm 0.2$ & $0.69 \pm 0.06$ & $1.34 \pm 0.29$ & $0.50 \pm 0.07$ \\
\hline
\end{tabular}

and Murphy, 2012). While no feed refusal was observed by Dänicke et al. (2005), the authors did find significant decreases in apparent passage rate in cannulated dairy cows fed $8.1 \mathrm{mg} / \mathrm{kg}$ DON$/ 7.2 \mathrm{mg} / \mathrm{kg}$ ZEN over four weeks. They concluded that this influenced rumen protein utilization, an important process in foregut fermenters such as cattle. In feeder claves, body weight was not significantly altered by exposure to $15-148 \mathrm{mg} / \mathrm{kg}$ FUM over 31 days (Osweiler et al., 1993).

\section{Blood chemistry assays}

For the blood biochemical energy indices, glucose, creatinine kinase nor triglycerides were significantly altered in treatment animals as compared to control animals (Table $2, P>0.20)$; these observations indicate that there were minimal implications to muscle energy production in beef cattle from DON/FUM exposure in the current experiment. $\mathrm{SDH}$ was also not significantly affected in treatment animals (Table $2, P>0.20$ ). In contrast, another study observed an increase in this glucose converting enzyme in response to FUM exposure in milk-fed calves (Mathur et al., 2001); and another which fed $3.0-8.3 \mathrm{mg} / \mathrm{kg}$ DON over 70 days to growing bulls (Dänicke et al., 2018).
Liver functionality was evaluated by a number of parameters which indicated minimal hepatic perturbations (Table 2). None of the variables measured were significantly different between groups but trends showed that AST levels in treatment-fed steers were slightly elevated during week 1 (71 U/l versus $66 \mathrm{U} / \mathrm{l}$ in control animals), while bile acids began at an elevated level in treatment steers but were lower than control fed steers by week 3 (Table 2). Treatment-fed steers showed slightly increased cholesterol levels after one week of consuming DON and FUM contaminated feed $(79 \mathrm{mg} / \mathrm{dl}$ at week one compared to $65 \mathrm{mg} / \mathrm{dl}$ baseline, Table 2), but this change was resolved for the remainder of the study. Furthermore, cholesterol alterations were not accompanied by any significant differences in glucose levels of treatment animals during this period when compared to control-fed steers (Table 2, $P>0.20$ ). Cholesterol has been proposed as an early indicator of FUM exposure in calves, due to its release from cell membranes as sphingolipid synthesis is disrupted (Osweiler et al., 1993). Osweiler et al. (1993) reported elevated AST, GGT, lactate dehydrogenase, bilirubin and cholesterol in calves chronically fed $148 \mathrm{mg} / \mathrm{kg}$ but not $31 \mathrm{mg} / \mathrm{kg}$ FUM from 10-31 days. Baker and Rottinghaus (1999) observed elevated AST and GGT in calves fed $440 \mathrm{mg} / \mathrm{kg}$ FUM for 32 weeks. Long-term 
(70 days) exposure to $3.0-8.3 \mathrm{mg} / \mathrm{kg}$ DON in growing beef steers also showed changes to AST, GGT, cholesterol and BHB (Dänicke et al., 2018). These data suggest that hepatotoxic endpoints require greater doses or length of exposure to Fusarium toxins than those used in the current experiment.

Changes in Sa/So have become a well-established biomarker of FUM exposure in monogastrics, as their ratios are altered by the competitive inhibition of sphingosine-Nacetyltransferase by fumonisins (Merrill et al., 1993). In finishing steers of the current trial, no significant changes in the ratio of $\mathrm{Sa} / \mathrm{So}$ were observed between groups for any time point (Table $2, P>0.20$ ), though sphinganine was numerically lower in treatment animals for week 2. In other work examining exposure of FUM in cattle, Mathur et al. (2001) observed an increase in sphinganine in calves given $1 \mathrm{mg}$ FUM/kg BW intravenously over 7 days. This contradiction to the current study may be due to the administrative route of the toxin or to the age of the animals used in these studies. Caloni et al. (2000) reported biotransformation of FUM within $72 \mathrm{~h}$ of incubation with rumen microbes ex vivo. While that study concluded that ruminant foregut biotransformation is a poor detoxification pathway for FUM (Caloni et al., 2000), even modest alterations to the FUM profile prior to the small intestine may contribute to the inconsistency in the $\mathrm{Sa} /$ So ratio biomarker in cattle, especially when combined with the observation that fumonisins are poorly absorbed in the intestine (Bouhet and Oswald, 2007). Furthermore, there is currently a limited understanding of endogenous sphingolipid metabolism in ruminants, and how circulating lipids are transferred throughout the animal in relation to dietary exposures to toxins such as FUM.

While control-fed animals had higher fibrinogen values at the beginning of the treatment phase, mycotoxin exposure indicated a trend for increasing fibrinogen levels by the end of the second week of exposure (600/517 for treatment/control animals, respectively, Table $3, P>0.20)$. This inflammatory marker parallels an increase in WBC count observed across all weeks for the treatment group, with differences after three weeks of exposure suggestive of a treatment-related effect (13402 versus $9277 \mathrm{WBC} / \mu \mathrm{l}$ for treatment and control-fed animals, respectively, Table $3, P>0.20)$. In addition, MCV showed a trend towards increasing across weeks 3-4 in treatment-fed steers (Table 3, P>0.20). Dänicke et al. (2018) also observed this phenomenon in steers exposed to DON. Elevated MCV indicates an increase in red blood cell size, which can be due to liver disease or folic acid deficiency (Nagao and Hirokawa, 2017), both of which follow disease sequelae associated with DON/FUM exposure.

In summary, treatment-fed animal blood biochemistry values suggest early signs of liver dysfunction and systemic
Table 3. Blood chemistry: complete blood count values of beef cattle exposed to Fusarium mycotoxins for 21 days, followed by a 14-day clearance period.

\begin{tabular}{|c|c|c|}
\hline & WBC (cells/pl) & $\operatorname{MCV}(\mathrm{fL})$ \\
\hline Baseline & - & - \\
\hline Control & $9,328 \pm 738$ & $37.9 \pm 0.8$ \\
\hline Treatment & $10,020 \pm 583$ & $38.5 \pm 0.8$ \\
\hline Week 1 & 0.70 & 0.70 \\
\hline Control & $9,475 \pm 544$ & $38.1 \pm 0.8$ \\
\hline Treatment & $10,028 \pm 385$ & $38.6 \pm 0.8$ \\
\hline Week 2 & 0.75 & 0.70 \\
\hline Control & $8,843 \pm 600$ & $38.3 \pm 0.7$ \\
\hline Treatment & $9,390 \pm 738$ & $38.7 \pm 0.9$ \\
\hline Week 3 & 0.23 & 0.23 \\
\hline Control & $9,277 \pm 788$ & $39.1 \pm 0.6$ \\
\hline Treatment & $13,402 \pm 1,719$ & $38.9 \pm 0.6$ \\
\hline Week 4 & 0.35 & 0.30 \\
\hline Control & $9,622 \pm 1,223$ & $39.7 \pm 0.6$ \\
\hline Treatment & $12,027 \pm 1,415$ & $39.6 \pm 0.7$ \\
\hline Week 5 & 0.30 & 0.30 \\
\hline Control & $10,212 \pm 1,289$ & $40.2 \pm 0.7$ \\
\hline Treatment & $14,000 \pm 2,242$ & $40.1 \pm 0.9$ \\
\hline \multicolumn{3}{|c|}{$\begin{array}{l}{ }^{1} \text { Treatment period lasted three weeks, followed by a 2-week clearance } \\
\text { period (weeks } 4 \text { and } 5 \text { ), and included } n=6 \text { animals per group. Values are } \\
\text { observed means } \pm \text { standard errors before any baseline value correction; } \\
\text { Benjamini-Hochberg adjusted } P \text {-values are indicated in italics. WBC = } \\
\text { white blood cell count; MCV = mean corpuscular value. }\end{array}$} \\
\hline
\end{tabular}

inflammation, while overall changes were not significant across the spectrum of measured parameters. This echoes the findings of Osweiler (1993), Seeling et al. (2006) and DiConstanzo and Murphy (2012). Another study which have explored the influence of additional variables such as vaccination on cattle exposed to DON and ZEN did find more drastic changes in serum biochemistry values, especially when animals were fed for longer periods of time, and across higher concentrations (Dänicke et al., 2018). Additional work with dairy cattle in the transition period (a period of acute physiological stressors and negative energy balance) showed that haemoglobin, haematocrit and erythrocyte counts were altered by DON and ZENcontaminated diets fed over 14 weeks (Dänicke et al., 2017). This emphasizes that identifying one or more biomarkers from changes in blood chemistry parameters to indicate Fusarium toxin exposure in beef cattle will need to take age of animal, dose and duration of exposure into consideration.

\section{Ruminal fluid assays}

The rumen is the main site of DON but not FUM metabolism: DON is readily converted into the less toxic de-epoxidized metabolite DOM-1 by the ruminal flora 
(EFSA, 2017), whereas FUM shows limited ruminal degradation (Caloni et al., 2000). Previous studies reported that ruminal $\mathrm{pH}$ in cattle did not appear to be impacted by DON or FUM in the feed (Caloni et al., 2000; Dänicke et al., 2005; Seeling et al., 2006); our study showed suggestive evidence for an alteration during week 2 of the treatment period for treatment-fed steers (Table $6, P=0.20$ ), while no such differences between treatment- and control-fed steers existed during the clearance phase (Table $4, P \geq 0.20$ ). No significant differences were seen for the ruminal fluid VFAs measured (Table 4, $P>0.20$ ). Dänicke et al. (2005) fed DON and ZEN to dairy cattle, while Caloni et al. (2000) observed in vitro incubation of FUM with ruminal fluid, with neither research team determining any fluctuations in VFAs. Seeling et al. (2006), however, showed a trend for lower acetate, propionate and isobutyrate, and higher total VFAs in dairy cattle exposed to varying concentrations of DON and ZEN.

Ruminal ammonia fluctuated between groups in a non-linear fashion across the treatment and clearance period (Table 4). Substantially higher ruminal ammonia concentrations observed in treatment-fed steers for week 1 were suggestive of altered rumen function in these animals early in the exposure period (3.38/1.90 $\mathrm{mg} \mathrm{NH}_{4} \mathrm{CL} / \mathrm{dl}$ for treatment/control Table 4, $P=0.14$ ). Week 5 showed high levels for both groups, possibly the result of the extended exposure to a high starch diet. Dänicke et al. (2005) showed significantly higher rumen fluid ammonia concentration in dairy cattle exposed to DON and ZEN, but concluded that it was due to changes in the cell wall of the wheat which was naturally infected with Fusarium.

\section{Faecal samples and organ measurements}

Constituents of the faecal samples are described in Table 5 and organ weights (liver, heart, lung, kidney and spleen, in $\mathrm{g} / \mathrm{kg}$ body weight) are presented in Table 6 . None of these normalized organ weights were significantly different between the treatment and control group at the end of the experiment $(P>0.05)$. Neither gross observations nor histopathology reports revealed meaningful differences between treatment- and control-fed steers for the liver biopsies taken on days 0 and 21, nor the liver and additional tissues submitted for day 35. Day 35 liver biopsies showed clusters of leukocytes and subtle vacuolation of hepatocytes in some animals from both groups. In previous works in this species, substantially higher levels of FUM exposure $(15-148 \mathrm{mg} / \mathrm{kg}$ in feeder calves) reported enlarged and haemorrhagic mesenteric lymph nodes, mild changes to liver tissue, and marked differences in the spleen; all changes were considered reversible (Osweiler et al., 1993). In agreement with the current study, Baker and Rottinghaus (1999) did not find any gross lesions, and observed only mild hepatic histologic changes in cattle fed $3.5 \mathrm{mg} / \mathrm{kg}$ FUM for 32 weeks. This study confirms that dietary exposure of finishing beef steers to DON and FUM at these levels is insufficient to cause significant gross or histological changes in organ size or appearance when fed over a short duration.

Table 4. Whole ruminal fluid parameters: volatile fatty acids, ammonia, protein and $\mathrm{pH}$ of beef cattle exposed to Fusarium mycotoxins for 21 days, followed by a 14-day clearance period. ${ }^{1}$

$\begin{array}{lllllll} & \text { Acetic acid }(\mathrm{mM}) & \text { Propionic acid }(\mathrm{mM}) & \text { Butyric acid }(\mathrm{mM}) & \text { Ammonia }\left(\mathrm{mg} \mathrm{NH}_{4} \mathrm{Cl} / \mathrm{dl}\right) & \text { Protein }(\boldsymbol{\mu g} \mathrm{BSA} / \mathrm{ml}) & \mathrm{pH} \\ \text { Baseline } & - & - & - & - & - & - \\ \text { Control } & 24.22 \pm 6.01 & 13.62 \pm 1.56 & 8.83 \pm 2.39 & 2.83 \pm 0.86 & 37.71 \pm 3.95 & 6.64 \pm 0.12 \\ \text { Treatment } & 29.67 \pm 4.49 & 14.72 \pm 2.14 & 6.82 \pm 0.77 & 2.04 \pm 0.35 & 37.53 \pm 1.96 & 6.67 \pm 0.17 \\ \text { Week 1 } & 0.81 & 0.66 & 0.66 & 0.14 \dagger & 0.20 \dagger & 0.95 \\ \text { Control } & 34.39 \pm 2.74 & 19.43 \pm 2.62 & 4.53 \pm 0.96 & 1.90 \pm 0.26 & 37.06 \pm 3.41 & 6.59 \pm 0.16 \\ \text { Treatment } & 30.93 \pm 3.60 & 25.76 \pm 4.56 & 7.28 \pm 1.50 & 3.38 \pm 0.58 & 50.77 \pm 5.74 & 6.62 \pm 0.33 \\ \text { Week 2 } & 0.66 & 0.66 & 0.66 & 0.66 & 0.10^{*} & 0.20 \dagger \\ \text { Control } & 27.88 \pm 3.29 & 16.25 \pm 2.64 & 5.22 \pm 1.21 & 4.53 \pm 1.67 & 35.50 \pm 2.09 & 6.97 \pm 0.08 \\ \text { Treatment } & 35.76 \pm 5.96 & 23.90 \pm 5.35 & 6.53 \pm 1.13 & 5.21 \pm 0.89 & 49.97 \pm 3.44 & 6.60 \pm 0.14 \\ \text { Week 3 } & 0.66 & 0.66 & 0.85 & 0.92 & 0.99 & 0.66 \\ \text { Control } & 25.03 \pm 1.11 & 21.63 \pm 3.94 & 5.70 \pm 0.78 & 7.39 \pm 2.97 & 38.06 \pm 4.80 & 6.70 \pm 0.10 \\ \text { Treatment } & 36.00 \pm 0.00 & 17.47 \pm 8.39 & 5.82 \pm 2.92 & 5.16 \pm 1.10 & 38.20 \pm 8.03 & 6.92 \pm 0.16 \\ \text { Week 4 } & 0.93 & 0.96 & 0.75 & 0.53 & 0.66 & 0.93 \\ \text { Control } & 36.03 \pm 4.56 & 23.51 \pm 5.31 & 8.05 \pm 1.64 & 2.95 \pm 0.80 & 37.04 \pm 4.76 & 6.72 \pm 0.11 \\ \text { Treatment } & 35.75 \pm 6.17 & 24.08 \pm 4.86 & 5.63 \pm 1.42 & 6.52 \pm 1.75 & 44.44 \pm 0.87 & 6.78 \pm 0.11 \\ \text { Week 5 } & 0.75 & 0.93 & 0.93 & 0.93 & 0.93 & 0.93 \\ \text { Control } & 35.97 \pm 5.09 & 12.04 \pm 3.14 & 6.46 \pm 1.13 & 10.32 \pm 3.54 & 31.39 \pm 2.14 & 7.03 \pm 0.08 \\ \text { Treatment } & 27.87 \pm 6.67 & 14.11 \pm 7.85 & 4.40 \pm 1.94 & 7.76 \pm 1.81 & 37.32 \pm 2.94 & 6.99 \pm 0.09\end{array}$

${ }^{1}$ Treatment period lasted three weeks, followed by a 2-week clearance period (weeks 4 and 5), and included $n=6$ animals per group. Values are observed means \pm standard errors before any baseline value correction; Benjamini-Hochberg adjusted $P$-values are indicated in italics; ${ }^{*}=\operatorname{adjusted} P$-value $\leq 0.10$; $\dagger$ adjusted $P$-values between 0.1 and 0.2 were considered suggestive evidence. BSA = bovine serum albumin. 
Table 5. Constituents of faecal samples of beef cattle exposed to Fusarium mycotoxins for 21 days, followed by a 14-day clearance period. ${ }^{1}$

\begin{tabular}{|c|c|c|c|c|c|c|c|c|c|c|}
\hline & $\begin{array}{l}\text { Nitrogen } \\
\text { (\%DM) }\end{array}$ & $\begin{array}{l}\text { Ammonium } \\
\text { nitrogen } \\
\text { (\%DM) }\end{array}$ & $\begin{array}{l}\text { Organic } \\
\text { nitrogen } \\
(\% \mathrm{CP})\end{array}$ & $\begin{array}{l}\text { Phosphorous } \\
\text { (\%DM) }\end{array}$ & $\begin{array}{l}\text { Phosphate } \\
\text { equivalent } \\
\text { (\%DM) }\end{array}$ & $\begin{array}{l}\text { Potassium } \\
\text { (\%DM) }\end{array}$ & $\begin{array}{l}\text { Potash } \\
\text { equivalent } \\
\text { (\%DM) }\end{array}$ & $\begin{array}{l}\text { Total } \\
\text { solids } \\
\text { (\%DM) }\end{array}$ & Ash (\%DM) & $\begin{array}{l}\text { Chloride } \\
\text { (\%DM) }\end{array}$ \\
\hline \multicolumn{11}{|l|}{ Baseline } \\
\hline Control & 2.021 & 0.005 & 2.016 & 0.571 & 1.309 & 1.667 & 2.008 & 92.73 & 6.22 & 0.16 \\
\hline $\begin{array}{l}\text { Treatment } \\
\text { Week } 1\end{array}$ & 1.878 & 0.004 & 1.874 & 0.533 & 1.221 & 1.66 & 2.000 & 90.54 & 6.77 & 0.13 \\
\hline Control & 1.731 & 0.003 & 1.728 & 0.495 & 1.135 & 1.916 & 2.308 & 90.00 & 6.77 & 0.90 \\
\hline $\begin{array}{l}\text { Treatment } \\
\text { Week } 2\end{array}$ & 1.501 & 0.003 & 1.498 & 0.335 & 0.767 & 0.999 & 1.203 & 89.99 & 3.98 & 0.14 \\
\hline Control & 1.939 & 0.009 & 1.93 & 0.505 & 1.158 & 1.61 & 1.94 & 89.41 & 6.36 & 0.16 \\
\hline $\begin{array}{l}\text { Treatment } \\
\text { Week } 3\end{array}$ & 1.760 & 0.009 & 1.751 & 0.366 & 0.839 & 1.082 & 1.303 & 89.47 & 4.49 & 0.11 \\
\hline Control & 1.858 & 0.009 & 1.849 & 0.419 & 0.960 & 1.311 & 1.579 & 88.63 & 5.94 & 0.18 \\
\hline $\begin{array}{l}\text { Treatment } \\
\text { Week } 4\end{array}$ & 1.707 & 0.006 & 1.701 & 0.392 & 0.897 & 1.206 & 1.452 & 88.77 & 4.39 & 0.15 \\
\hline Control & 1.928 & 0.006 & 1.922 & 0.412 & 0.944 & 1.631 & 1.965 & 89.43 & 5.79 & 0.21 \\
\hline $\begin{array}{l}\text { Treatment } \\
\text { Week } 5\end{array}$ & 2.171 & 0.012 & 2.159 & 0.59 & 1.352 & 1.613 & 1.943 & 89.07 & 6.11 & 0.22 \\
\hline Control & 2.090 & 0.006 & 2.084 & 0.535 & 1.226 & 1.511 & 1.820 & 89.60 & 6.01 & 0.21 \\
\hline Treatment & 1.583 & 0.003 & 1.580 & 0.358 & 0.821 & 1.288 & 1.551 & 89.44 & 4.75 & 0.16 \\
\hline
\end{tabular}

${ }^{1}$ Treatment period lasted three weeks, followed by a 2-week clearance period (weeks 4 and 5), and included $n=6$ animals per group. DM = dry matter; $\mathrm{CP}=$ crude protein. Values are observational statistics of proximate analysis of weekly pooled samples.

Table 6. Organ weights at necropsy (end of clearance) of beef cattle exposed to Fusarium mycotoxins for 21 days, followed by a 14-day clearance period. ${ }^{1}$

\begin{tabular}{|c|c|c|c|c|c|}
\hline & Liver (g/kg BW) & Heart (g/kg BW) & Lung (g/kg BW) & Kidney (g/kg BW) & Spleen (g/kg BW) \\
\hline Week 5 & 0.41 & 0.16 & 0.54 & 0.31 & 0.73 \\
\hline Control & $12.38 \pm 1.73$ & $3.55 \pm 0.46$ & $11.72 \pm 0.90$ & $1.30 \pm 0.05$ & $1.53 \pm 0.18$ \\
\hline Treatment & $13.19 \pm 1.53$ & $3.94 \pm 0.44$ & $12.09 \pm 1.17$ & $1.21 \pm 0.16$ & $1.60 \pm 0.30$ \\
\hline
\end{tabular}

\section{Conclusions}

Our study examined physiological responses in beef cattle to the Fusarium mycotoxins FUM and DON more thoroughly than previously described, and did so across multiple time points of treatment and clearance phases. Most of the physiological variables which showed minor perturbations in treatment animals receiving a diet of $1.7 \mathrm{mg}$ DON and 3.2 mg FUM per kg TMR for three weeks returned to levels that were similar to control animals after a two week washout period. The only biological marker which did not show recovery from the treatment to the clearance period was body weight. Thus, the clearance period of the crossover model appears to return the animal to a naïve state for most of the molecular parameters measured; however, the inability of treatment animals to regain optimal growth rates could impact overall production. Performance values showed a pattern towards equilibration with each successive week on non-contaminated feed in the clearance phase; thus we recommend extending the clearance period in order to allow animals to return to weekly body weights that are comparative to the control group when utilizing the cross-over model. As the EFSA 2017 and 2018 reviews summarised, and we further substantiate here, the risk of adverse health effects from feed containing average levels of DON or FUM to fattening beef cattle is considered low. 
While some conclusions can be drawn from this study, we recommend increasing the number of animals per group to improve statistical analysis of the variables measured. The low dose and exposure window used in this study indicate that similar animals may be at greater risk of health events in response to these toxin levels than previously addressed. Further, while the animals received dietary stress in the form of a high starch concentrate diet, these animals were not exposed to environmental stressors often experienced by commercially raised animals at this life state (e.g. increased stocking density and exposure to harsh weather). Lastly, additional, higher concentrations or longer exposures to the mycotoxins studied should be considered to more definitively demonstrate health perturbations in the animals.

\section{Supplementary material}

Supplementary material can be found online at https://doi. org/10.3920/WMJ2020.2567.

Table S1. Sample days in crossover experiment investigating response of beef cattle exposed to Fusarium mycotoxins for 21 days, followed by a 14-day clearance period.

Table S2. Proximate analysis of total mixed rations and major constituents in crossover experiment investigating response of beef cattle exposed to Fusarium mycotoxins for 21 days, followed by a 14-day clearance period.

Table S3. Gross animal and energy-protein variables measured in beef cattle exposed to Fusarium mycotoxins for 21 days, followed by a 14-day clearance period.

Table S4. Blood chemistry: mineral metabolism/electrolyte indices of beef cattle exposed to Fusarium mycotoxins for 21 days, followed by a 14-day clearance period.

Table S5. Blood chemistry: complete blood count values and whole ruminal fluid parameters of beef cattle exposed to Fusarium mycotoxins for 21 days, followed by a 14-day clearance period.

Materials and methods S1. Expanded materials and methods.

\section{Conflict of interest}

The authors declare no conflict of interest.

\section{Acknowledgements}

We would like to thank BIOMIN Holding GmbH (Getzersdorf, Austria) for funding this study. We would also like to acknowledge Seth Spencer and the Farm Services staff of the OSU Department of Animal \& Rangeland
Sciences for the care and feeding of the cattle; Linda Blythe, Katherine Swanson and Kari Carola for their assistance with sampling; Gita Cherian for the use of her laboratory space; and Morrie Craig for his input on this project.

\section{References}

Altpeter, F. and Posselt, U.K., 1994. Production of high quantities of 3-acetyldeoxynivalenol and deoxynivalenol. Applied Microbiology and Biotechnology 41: 384-387.

Baker, D.C. and Rottinghaus, G.E., 1999. Chronic experimental fumonisin intoxication of calves. Journal of Veterinary Diagnostic Investigation 11: 289-292.

Bate, S.T. and Boxall, J., 2008. The construction of multi-factor crossover designs in animal husbandry studies. Pharmaceutical Statistics 7: 179-194.

Bondy, G.S. and Pestka, J.J., 2000. Immunomodulation by fungal toxins. Journal of Toxicology and Environmental Health: Part B, Critical Reviews 3: 109-143.

Bouhet, S. and Oswald, I.P., 2007. The intestine as a possible target for fumonisin toxicity. Molecular Nutrition and Food Research 51: 925-931.

Broderick, G.A. and Kang, J.H., 1980. Automated simultaneous determination of ammonia and total amino acids in ruminal fluid and in vitro media. Journal of Dairy Science 63: 64-75.

Caloni, F., Spotti, M., Auerbach, H., Op den Camp, H., Fink Gremmels, J. and Pompa, G., 2000. In vitro metabolism of fumonisin $\mathrm{B}_{1}$ by ruminal microflora. Veterinary Research Communications 24: 379-387.

Cammack, K.M., Austin, K.J., Lamberson, W.R., Conant, G.C. and Cunningham, H.C., 2018. Ruminant nutrition symposium: tiny but mighty: the role of the rumen microbes in livestock production. Journal of Animal Science 96: 752-770.

Dänicke, S., Matthäus, K., Lebzien, P., Valenta, H., Stemme, K., Ueberschaer, K.H., Razzazi-Fazeli, E., Böhm, J.A. and Flachowsky, G., 2005. Effects of Fusarium toxin-contaminated wheat grain on nutrient turnover, microbial protein synthesis and metabolism of deoxynivalenol and zearalenone in the rumen of dairy cows. Journal of Animal Physiology and Animal Nutrition 89: 303-315.

Dänicke, S., Winkler, J., Meyer, U., Frahm, J. and Kersten, S., 2017. Haematological, clinical-chemical and immunological consequences of feeding Fusarium toxin contaminated diets to early lactating dairy cows. Mycotoxin Research 33: 1-13.

Dänicke, S., Winkler, J., Meyer, U., Kersten, S., Wernike, K., Beer, M. and Frahm, J., 2018. Antibody response of growing German Holstein bulls to a vaccination against bovine viral diarrhea virus (BVDV) is influenced by Fusarium toxin exposure in a non-linear fashion. Mycotoxin Research 34: 123-139.

Debevere, S., De Baere, S., Haesaert, G., Rychlik, M., Croubels, S. and Fievez, V., 2019. In vitro rumen simulations show a lower disappearance of deoxynivalenol, nivalenol, zearalenone and enniatin $B$ at conditions of rumen acidosis and at dry conditions. Abstracts of the $41^{\text {st }}$ Mycotoxin workshop, pp. 61.

DiCostanzo, A. and Murphy, M., 2012. Strategies for feeding mycotoxin and mold contaminated grains to cattle. University of Minnesota. Available at: https://tinyurl.com/yax9pxyj 
Doster, E., Rovira, P., Noyes, N.R., Burgess, B.A., Yang, X., Weinroth, M.D., Lakin, S.M., Dean, C.J., Linke, L., Magnuson, R., Jones, K.I., Boucher, C., Ruiz, J., Belk, K.E. and Morley, P.S., 2018. Investigating effects of tulathromycin metaphylaxis on the fecal resistome and microbiome of commercial feedlot cattle early in the feeding period. Frontiers in Microbiology 9: 1715. https://doi.org/10.3389/ fmicb.2018.01715

European Commission (EC), 2006. Commission Recommendation of 17 August 2006 on the presence of deoxynivalenol, zearalenone, ochratoxin A, T-2 and HT-2 and fumonisins in products intended for animal feeding. Official Journal of the European Union L 118: 1111-1113.

European Food Safety Authority, Panel on Contaminants in the Food Chain (EFSA), 2017. Risks to human and animal health related to the presence of deoxynivalenol and its acetylated and modified forms in food and feed. EFSA Journal 15: e04718.

European Food Safety Authority, Panel on Contaminants in the Food Chain (EFSA), 2018. Risks for animal health related to the presence of fumonisins, their modified forms and hidden forms in feed. EFSA Journal 16: e05242.

Fink-Gremmels, J., 2008. The role of mycotoxins in the health and performance of dairy cows. Veterinary Journal 176: 84-92.

Grenier, B., Schwartz-Zimmermann, H.E., Caha, S., Moll, W.D., Schatzmayr, G. and Applegate, T.J., 2015. Dose-dependent effects on sphingoid bases and cytokines in chickens fed diets prepared with Fusarium verticillioides culture material containing fumonisins. Toxins 7: 1253-1272.

Gruber-Dorninger, C., Jenkins, T. and Schatzmayr, G., 2019. Global mycotoxin occurrence in feed: a ten-year survey. Toxins 11: 375.

Joffe, A.Z., 1986. Fusarium species - their biology and toxicology. John Wiley \& Sons Inc., Hoboken, NJ, USA, 412 pp.

Kaps, M. and Lamberson, W., 2009. Biostatistics for animal science: an introductory text. CAB International, Wallingford, UK, 504 pp.

Korosteleva, S.N., Smith, T.K. and Boermans, H.J., 2007. Effects of feedborne Fusarium mycotoxins on the performance, metabolism, and immunity of dairy cows. Journal of Dairy Science 90: 3867-3873.

Korosteleva, S.N., Smith, T.K. and Boermans, H.J., 2009. Effects of feed naturally contaminated with Fusarium mycotoxins on metabolism and immunity of dairy cows. Journal of Dairy Science 92: 1585-1593.

Mathur, S., Constable, P.D., Eppley, R.M., Waggoner, A.L., Tumbleson, M.E. and Haschek, W.M., 2001. Fumonisin $B_{1}$ is hepatotoxic and nephrotoxic in milk-fed calves. Toxicological Sciences 60: 385-396.

Merrill, A.H., Van Echten, G., Wang, E. and Sandhoff, K., 1993. Fumonisin $B_{1}$ inhibits sphingosine (sphinganine) $\mathrm{N}$-acyltransferase and de novo sphingolipid biosynthesis in cultured neurons in situ. Journal of Biological Chemistry 268: 27299-27306.

Morgavi, D.P. and Riley, R.T., 2007. An historical overview of field disease outbreaks known or suspected to be caused by consumption of feeds contaminated with Fusarium toxins. Animal Feed Science and Technology 137: 201-212.

Nagao, T. and Hirokawa, M., 2017. Diagnosis and treatment of macrocytic anemias in adults. Journal of General and Family Medicine 18: 200-204.
Novak, B., Vatzia, E., Springler, A., Pierron, A., Gerner, W., Reisinger, N., Hessenberger, S., Schatzmayr, G. and Mayer, E., 2018. Bovine peripheral blood mononuclear cells are more sensitive to deoxynivalenol than those derived from poultry and swine. Toxins 10: 152.

Osweiler, G.D., Kehrli, M.E., Stabel, J.R., Thurston, J.R., Ross, P.F. and Wilson, T.M., 1993. Effects of fumonisin-contaminated corn screenings on growth and health of feeder calves. Journal of Animal Science 71: 459-466.

Paschal, J.C., 2017. Some thoughts on body condition scoring of cows. Expert Connection: Frontline Beef Producer: 14-15. Available at: https://tinyurl.com/y7wyv6jw

Pestka, J.J., Yike, I., Dearborn, D.G., Ward, M.D.W. and Harkema, J.R., 2008. Stachybotrys chartarum, trichothecene mycotoxins, and damp building-related illness: new insights into a public health enigma. Toxicological Sciences 104: 4-26.

Prelusky, D.B., Trenholm, H.L. and Savard, M.E., 1994. Pharmacokinetic fate of 14C-labelled fumonisin $B_{1}$ in swine. Natural Toxins 2: 73-80.

R Core Team, 2019. R: a language and environment for statistical computing. R Foundation for Statistical Computing, Vienna, Austria. Available at: https://www.R-project.org/

Seeling, K., Lebzien, P., Dänicke, S., Spilke, J., Südekum, K.-H. and Flachowsky, G., 2006. Effects of level of feed intake and Fusarium toxin-contaminated wheat on rumen fermentation as well as on blood and milk parameters in cows. Journal of Animal Physiology and Animal Nutrition 90: 103-115.

Sobrova, P., Adam, V., Vasatkova, A., Beklova, M., Zeman, L. and Kizek, R., 2010. Deoxynivalenol and its toxicity. Interdisciplinary Toxicology 3: 94-99.

Streit, E., Schwab, C., Sulyok, M., Naehrer, K., Krska, R. and Schatzmayr, G., 2013. Multi-mycotoxin screening reveals the occurrence of 139 different secondary metabolites in feed and feed ingredients. Toxins 5: 504-523.

US Food and Drug Administration, 2018a. Guidance for industry: fumonisin levels in human foods and animal feeds. US Food and Drug Administration, Rockville, MD, USA. Available at: https:// tinyurl.com/y84rg36x

US Food and Drug Administration, 2018b. Guidance for industry and FDA: advisory levels for deoxynivalenol (DON) in finished wheat products for human consumption and grains and grain by-products used for animal feed. US Food and Drug Administration, Rockville, MD, USA. Available at: https://tinyurl.com/yb4zgc5u

US Grains Council, 2016. Corn harvest quality report 2016-17. US Grains Council, Washington, DC, USA, pp. 76.

Valgaeren, B., Théron, L., Croubels, S., Devreese, M., De Baere, S., Van Pamel, E., Daeseleire, E., De Boevre, M., De Saeger, S., Vidal, A., Di Mavungu, J.D., Fruhmann, P., Adam, G., Callebaut, A., Bayrou, C., Frisée, V., Rao, A.-S., Knapp, E., Sartelet, A., Pardon, B., Deprez, P. and Antonissen, G., 2019. The role of roughage provision on the absorption and disposition of the mycotoxin deoxynivalenol and its acetylated derivatives in calves: from field observations to toxicokinetics. Archives of Toxicology 93: 293-310. 
